\section{Integrated Electron and X-Ray Induced Microbeam XRF in the SEM}

\author{
Brian J. Cross ${ }^{*}$ and Kenny C. Witherspoon ${ }^{* *}$ \\ ${ }^{*}$ CrossRoads Scientific or **IXRF Systems, Inc. \\ briancross@ieee.org, kennyw@ixrfsystems.com
}

Energy-Dispersive X-Ray Spectroscopy (ED-XRS or EDS) is a powerful and easy-to-use technique for the elemental analysis of a wide variety of materials. Most commonly, this technique is called XRay Fluorescence (XRF), which classically uses $\mathrm{x}$-ray photon sources to excite the sample. A Scanning Electron Microscope (SEM), of course, uses electrons as the excitation source for microbeam x-ray spectroscopy together with sample imaging using characteristic $\mathrm{x}$ rays and/or secondary electrons. These two XRS techniques are used independently, although often the same sample is analysed by both, to provide complementary information.

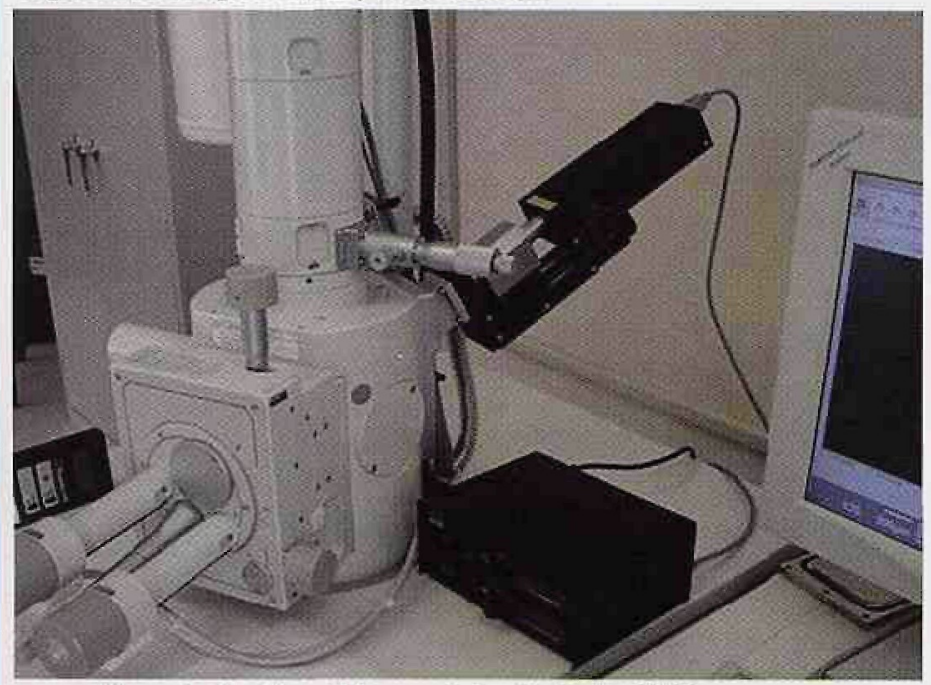

Figure 1. Small-spot $f X x$-ray tube attached to SEM

The advantages of both techniques have been reviewed several times [e.g. 1,2], SEM-EDS being more suited to imaging and microbeam quantitative compositional analysis and maps, and XRF more suited to accurate quantitative analysis, especially for trace elements, while analyzing a much larger area. One weak area of routine laboratory XRF is for low-atomic-number elements, where the excitation efficiencies for low-energy $\mathrm{x}$-rays are very poor. In these cases, SEMEDS analysis can often be better. Conversely, with an $\mathrm{x}$-ray source,

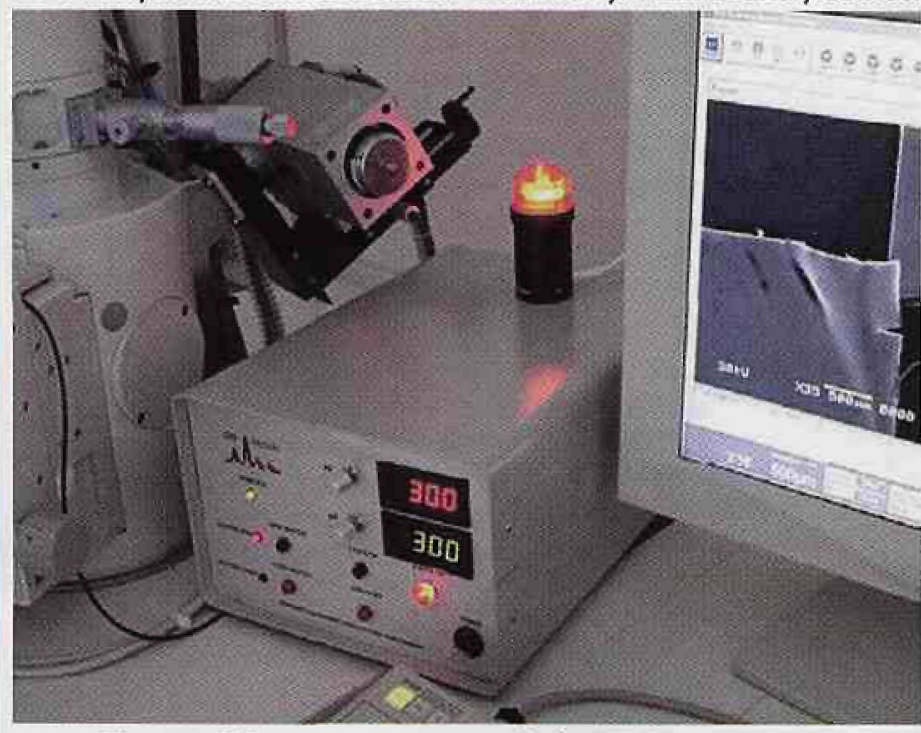

Figure 2. $X$-Beam $x$-ray source attached to SEM

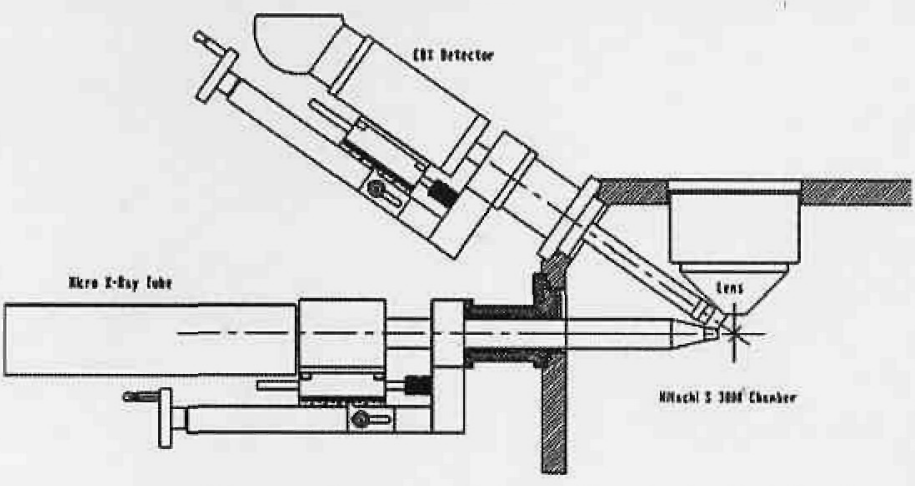

Figure 3. Diagram of small-spot $\mathrm{fX} x$-ray tube attached to SEM, also showing EDS detector

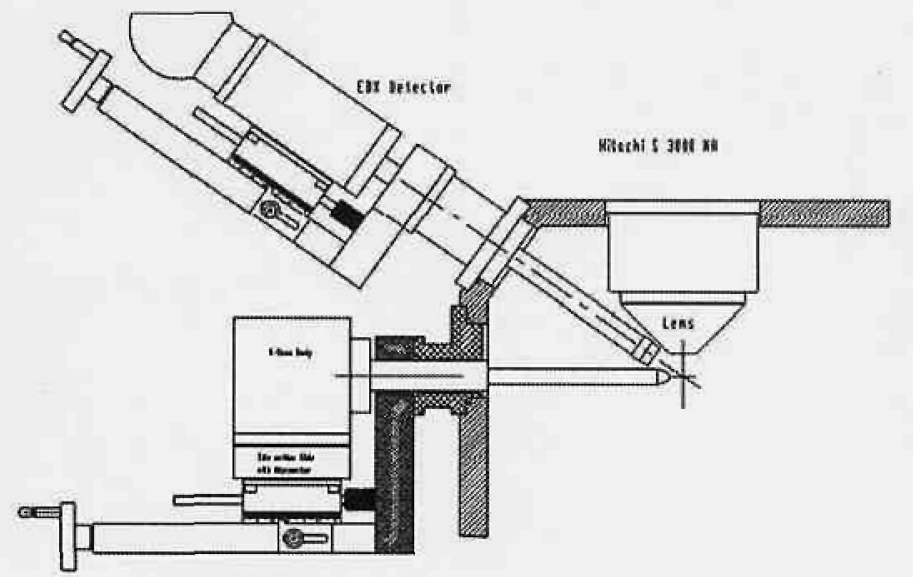

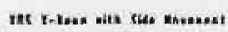

Figure 4. . Diagram of X-Beam x-ray source attached to $S E M$, also showing EDS detector

there is no need to coat the sample as charging is virtually nonexistent when using $\mathrm{x}$-ray photon excitation.

One can take advantage of the fact that most SEM-EDS microanalysis systems already have a high-quality EDS detector, with an ultrathin window that allows the analysis of critical light elements. Therefore, to enable good-quality XRF within an SEM, one only needs a suitable $X$-ray source to have both XRF and electron-beam $\mathrm{x}$-ray spectroscopy within the same chamber, in vacuo or in air, as appropriate for the sample.

Several attempts have been made to add XRF to SEMs, using the standard EDS detectors already in place $[3,4]$. Most of these used the electron beam to create the fluorescing $\mathrm{x}$-rays with a thin transmission-target foil placed between the beam and the sample. The main problem with this approach was the low incident $\mathrm{x}$-ray flux onto the sample, especially if the analysis area ( $\mathrm{x}$-ray beam) is restricted. The advantages of XRF (e.g., improved sensitivities and peak-to-background ratios) were then lost because of the low count rates achieved.

This problem can be solved by attaching a separate $x$-ray source onto the SEM, with flux outputs orders of magnitude higher than those produced by low-current SEM beams in transmission foils. By restricting the sample analysis area with apertures or active focusing optics, one can still achieve count rates in these small areas that are typical of standalone XRF spectrometers, with all the advantages of the XRF technique $[5,6]$.

In the first implementation (Figure 1), a re-entrant close-coupled low-power (3-4W) transmission-target tube $(f X)$ is shown, with an integrated aperture assembly that collimates the $x$-ray beam in the range of 0.5 to $5 \mathrm{~mm}$, depending upon the aperture. This tube can operate up to $35 \mathrm{kV}$, and does not require any active cooling. 
From Research to Reality

$\mathrm{X}$-ray Fluorescence for your Scanning Electron Microscope

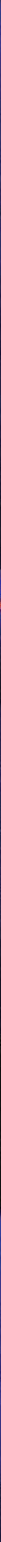
possible depending on the $\mathrm{X}$-ray souree being used.

\section{Applications:}

Electron Beam

-Turns your SEM into a XRF analyzer, complements your existing EDX

-Trace detection, down to low ppm levels

-Use of higher-energy lines, which have less peak

overlap

-Better counting statistics for trace concentrations

-Forensic applications replacing costly benchtop XRF

-Thickness measurements for thin film applications

-Analyze non conductive samples

-X-ray mapping with either electron or X-ray sources

IXIR Systems, Inc, 15715 Brookford Dr., Houston, TX 77059, Tel(281)286-6485 Fax(281)286-2660 
Knife-edge scan of Mo $K \alpha$ x rays directly from the $X$-Beam

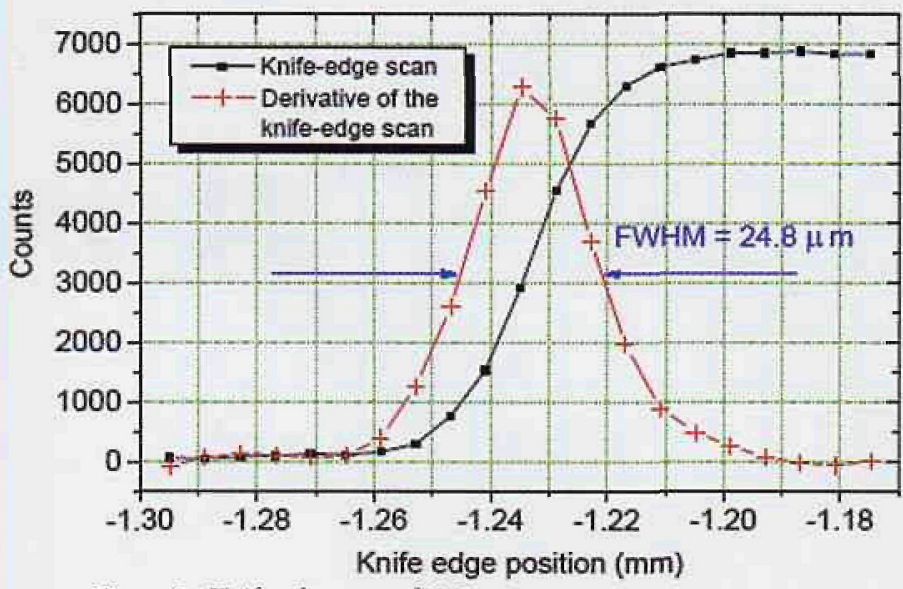

Figure 5, Knife-edge scan of X-Beam

In a second implementation, an X-Beam assembly is shown attached to the SEM in Figure 2. The X-Beam is a combination of medium-power $\mathrm{x}$-ray tube (up to $50 \mathrm{~W}$ ) with an integral polycapillary that focuses the $\mathrm{x}$-ray beam down to about 50 microns at the sample. In addition, this source has an integral shutter so the beam can be on continuously, even if the SEM chamber is opened. An integral air-cooling system is available for the highest power operation (50 $\mathrm{kV}, 1 \mathrm{~mA}$ ), or the tube can be operated at a lower power without any cooling.

The internal cross-sectional drawings for mounting each of these tubes are shown in Figures 3 and 4. These drawings reflect the Hitachi 3000 SEM with a horizontal port, with an $X Y$ stage that must be tilted toward the tube. Other SEMs, such as shown in Figures 1

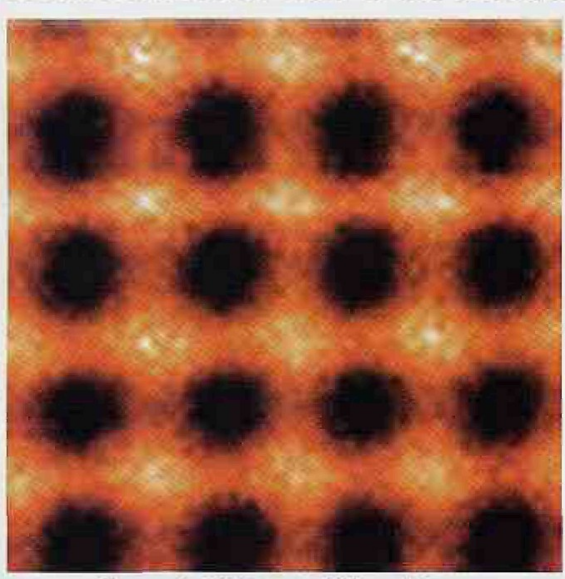

Figure 6. XY scan of Cu grid

integrated. The result is a compact dual-purpose instrument for imaging and quantitative analysis of a variety of sample types. Both of the $\mathrm{x}$-ray source configurations discussed above have been implemented without any interference with the normal SEM operation.

A knife-edge scan is shown in Figure 5, demonstrating the spot size achievable with the X-Beam device.

A practical example of the X-Beam in the SEM is shown in Figure 6 for an $X Y$ stage scan of a $\mathrm{Cu}$ grid with a 125 -micron pitch and a 12-micron bar thickness [6].

A comparison of spectra from a glass standard is shown in Figure 7. This shows the spectra from the electron beam, the $f X$ tube, and the $X$-Beam.

Minimum Detection Limits (MDLs) were calculated from each of the spectra in Figure 7, for the glass standard, and Table 1 shows the results.

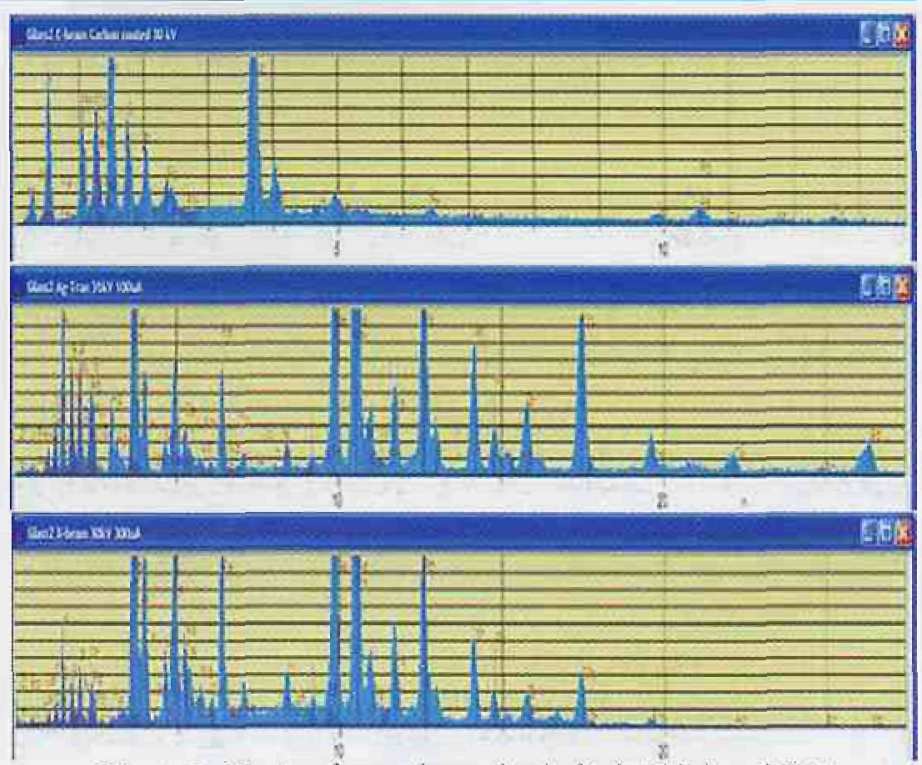

Figure 7. Spectra from e-beam (top), $f X$ (middle) and X-Beam (bottom)

From this table one can see that for light elements, the e-beam analysis is comparable or better, whereas for heavier elements (higher-energy $\mathrm{x}$ rays), the $\mathrm{x}$-ray sources give lower detection limits, demonstrating the advantages of the two techniques.

Finally, the following figures show some examples of $x$-ray mapping, using the SEM $X Y$ stage to move the sample, while analysing using either the $X$-ray or e-beam source. Figure 8 shows the $X Y$ scan $\mathrm{X}$-ray map taken using the X-Beam source, and the spectra for the complete maps using the e-beam and the X-Beam. Again the spectra show qualitatively the difference in the optimum excitation energy ranges for each technique.

\begin{tabular}{|r|c|c|c|c|}
\hline \multicolumn{5}{|c|}{$\begin{array}{c}\text { Table 1. Minimum Detection Limits from (a) SEM } \\
\text { e-beam, (b) X-Beam, and (c) Ag-target } f \text { tube. }\end{array}$} \\
\hline & Given & E-beam & X-beam & $f X$ \\
\hline Elt & $(W t . \%)$ & $M D L$ & $M D L$ & $M D L$ \\
\hline $\mathrm{Mg}$ & 6.03 & 0.164 & 0.747 & 0.466 \\
\hline $\mathrm{Al}$ & 10.06 & 0.157 & 0.390 & 0.274 \\
\hline $\mathrm{Si}$ & 1.87 & 0.160 & 0.260 & 0.188 \\
\hline $\mathrm{P}$ & 2.18 & 0.132 & 0.136 & 0.092 \\
\hline $\mathrm{Ca}$ & 10.01 & 0.108 & 0.037 & 0.049 \\
\hline $\mathrm{V}$ & 0.84 & 0.132 & 0.032 & 0.040 \\
\hline $\mathrm{Fe}$ & 0.42 & 0.147 & 0.015 & 0.018 \\
\hline $\mathrm{Ge}$ & 1.04 & 0.274 & 0.009 & 0.013 \\
\hline $\mathrm{As}$ & 1.67 & 0.339 & 0.009 & 0.015 \\
\hline $\mathrm{Sr}$ & 0.42 & 0.803 & 0.006 & 0.016 \\
\hline $\mathrm{Zr}$ & 0.15 & 1.220 & 0.010 & 0.018 \\
\hline $\mathrm{Mo}$ & 0.67 & 2.299 & 0.017 & 0.019 \\
\hline $\mathrm{Sb}$ & 1.67 & 0.321 & 0.130 & 0.178 \\
\hline $\mathrm{La}$ & 0.85 & 0.390 & 0.122 & 0.148 \\
\hline $\mathrm{Ce}$ & 0.85 & 0.388 & 0.120 & 0.147 \\
\hline $\mathrm{W}$ & 0.32 & 0.838 & 0.033 & 0.041 \\
\hline
\end{tabular}




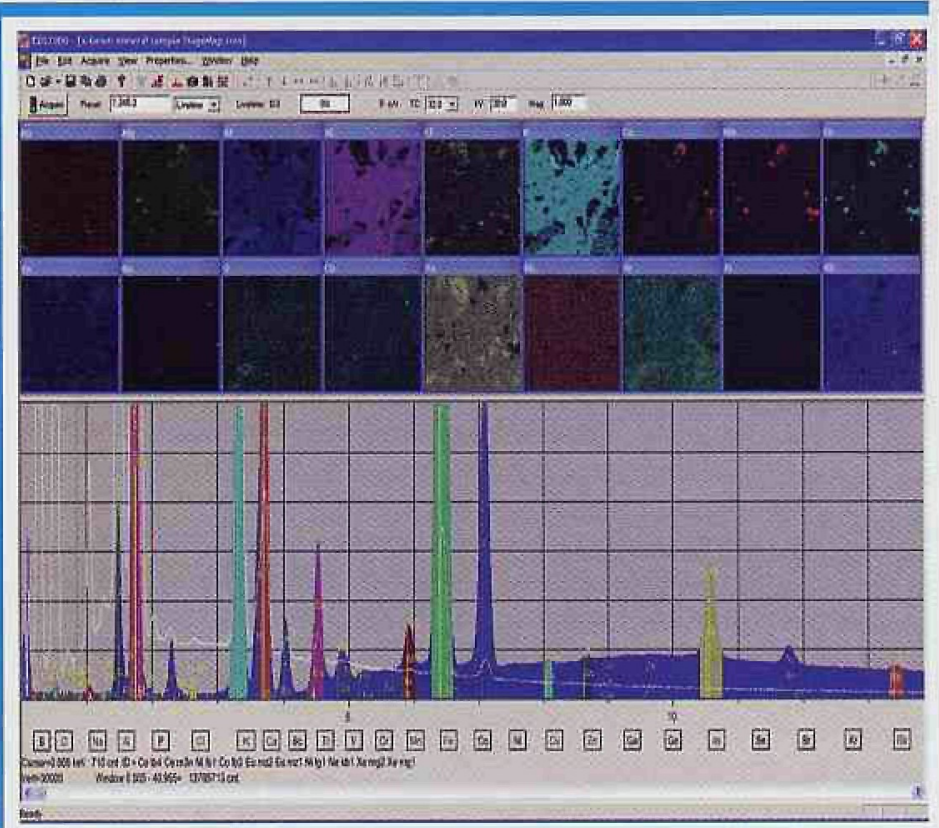

Figure 8. X-ray map using X-Beam and average spectra from both e-beam and $X$-Beam sources

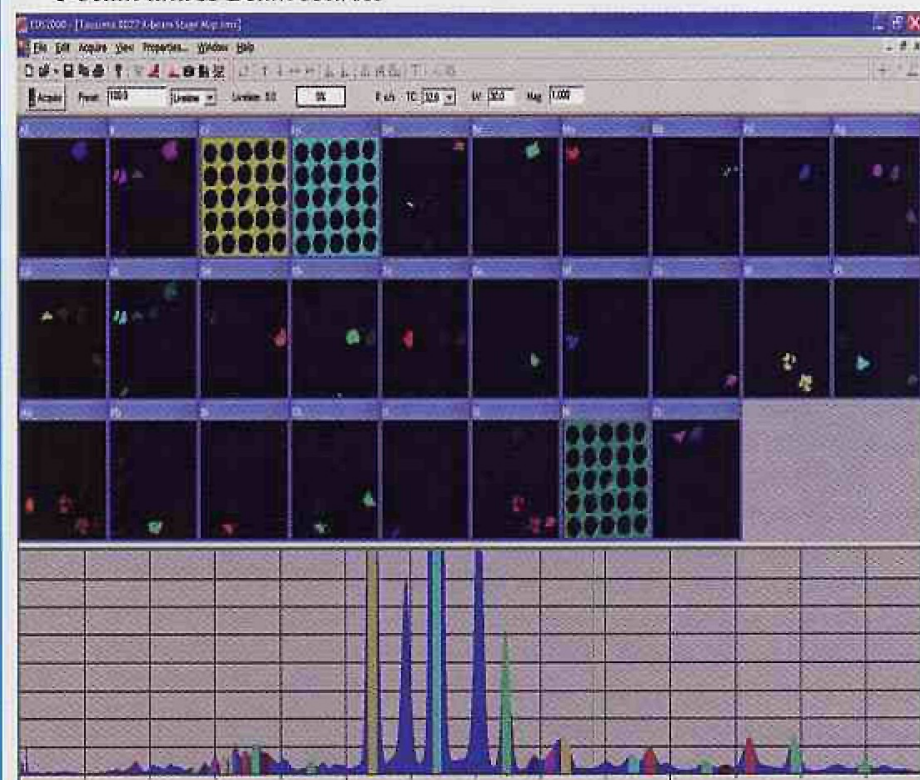

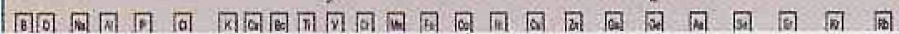

Figure 9. X-ray map \& average spectrum using X-Beam

Figure 9 shows a $X Y$ stage scan $\mathrm{X}$-ray map for a Tousimis 8207 elemental standard, showing the individual maps for each standard element.

The authors would like to acknowledge the help from several people, including Rich Lamb and Per Sjoman of IXRF Systems, Ning Gao, Tom Bievenue and Ian Radley of X-Ray Optical Systems (XOS), Jim Nicolino of AAT and Clark Turner of Moxtek. X-Beam is a trademark of XOS, and $f X$ is a trademark of IXRF Systems.

\section{References}

[1] B.].Cross and J.E.Augenstine, Adv. X-Ray Analysis, 34, 57 (1991).

[2] M.C.Nichols, D.R.Boehme, R.W.Ryon, D.C.Wherry, B.J.Cross and G.Aden, Adv. XRay Analysis, 30, 45 (1987).

[3] L.M.Middleman and J.D.Geller, Scanning Electron Microscopy, IITRI, part 1171 (1976)

[4] B.Linnemann and L.Reimer, Scanning 1109 (1978).

[5] B.J.Cross and K. Witherspoon, paper presented at Denver X-Ray Conference, Denver, $\mathrm{CO}$ (August 2003)

[6] N.Gao, T.Bievenue, I.Radley, J.Nicolino, K.Witherspoon and B.J.Cross, paper presented at M\&M Conference, San Antonio, TX (2003).

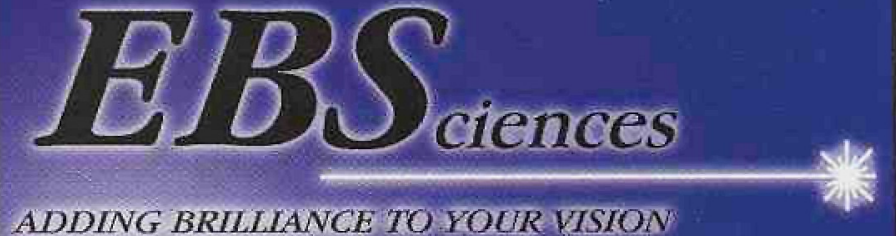

ADDING BRILIIANCE TO YOUR VISION

Exclusive U.S. Distriliutor for:

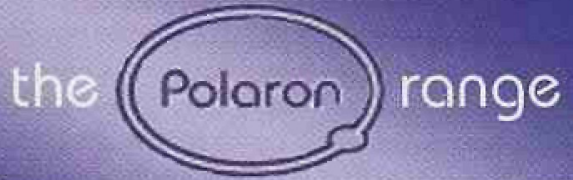

\section{of EM Advanced Preparation Instruments}

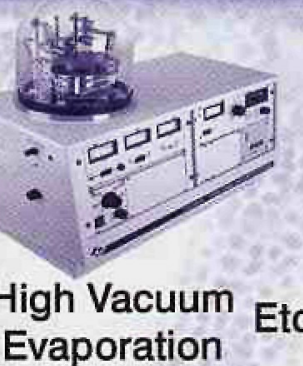

Evaporation

Plasma

Etching/ashing

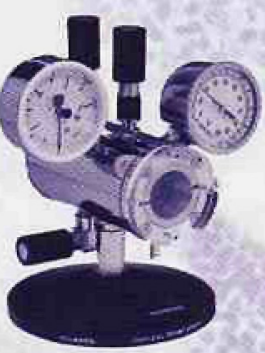

Critical Point Drying
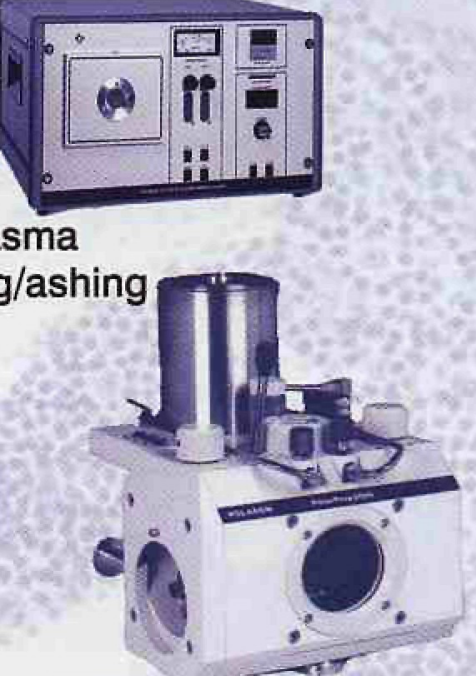

Cryo-SEM

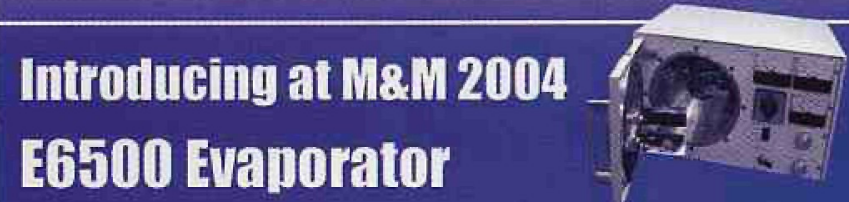

Low Gost - Full Features - Revolutionary Design

\section{Energy Beam Sciences Inc.}

\section{0-992-9037 or $413-786-9322$ \\ email:ebs@ebsciences.com \\ www.ebsciences.com}

See us at M\&M in Savannah, GA. Booth \#721 